\title{
Knowledge and Perception Towards Zika Outbreak In A Dental Institute
}

\author{
Manavpreet Singh ${ }^{1}$, Karanprakash Singh ${ }^{2}$, Mahijeet Singh Puri ${ }^{2}$, Chitra Anandani ${ }^{3}$, Harinder Pal Singh ${ }^{2}$ and Anjali Sharma ${ }^{1}$ \\ ${ }^{1}$ Luxmi Bai Institute of Dental Sciences \& Hospital, Patiala, India \\ ${ }^{2}$ Department of Public Health dentistry, Luxmi Bai Institute of Dental Sciences \& Hospital, Patiala, India \\ ${ }^{3}$ Department of Oral Pathology \& Microbiology, Luxmi Bai Institute of Dental Sciences \& Hospital, Patiala, India \\ *Corresponding authors: Manavpreet Singh, Luxmi Bai Institute of Dental Sciences \& Hospital, Patiala, India, Tel: +918142656336; E-mail: \\ dentalhealthcare2075@gmail.com
}

Received date: February 28, 2017; Accepted date: March 11, 2017; Published date: March 22, 2017

Copyright: (C) 2017 Singh M, et al. This is an open-access article distributed under the terms of the Creative Commons Attribution License, which permits unrestricted use, distribution, and reproduction in any medium, provided the original author and source are credited.

\begin{abstract}
Objective: The objective of the study is to evaluate the level of knowledge and perception towards Zika virus (ZIKA) outbreak in a dental institute as this vector borne virus has become a major public health concern worldwide.

Materials and Methods: A cross sectional study was conducted among 177 persons including interns, Bachelor of Dental Surgery (BDS) and Master of Dental Surgery (MDS) faculty. A wide variety of questions on the study topic including, basic knowledge and other characteristic features of ZIKA virus and its prevention and treatment modalities. Student's t test and One way ANOVA were used to find the significance at $p<0.05$.
\end{abstract}

Results: Overall $61.7 \%$ had correct views about ZIKA outbreak. The findings showed that $90 \%$ participants possessed knowledge about the viral origin of the condition. It was further revealed that almost $88 \%$ practitioners were aware about the mosquito bite to be the main cause of the spread of ZIKA infection. Moreover, only $29 \%$ correctly responded about the incubation period of ZIKA virus. It was also noticed that female participants had greater knowledge regarding ZIKA. The results showed significant differences in the mean values according to the level of education.

Conclusion: It was revealed that all the participants had adequate knowledge on the topic of ZIKA and the scores almost increased with proceeding age and education.

Keywords: Dental setting; Knowledge; ZIKA virus

\section{Introduction}

ZIKA virus is a well known entity today, with no major background in yesteryears. It has emerged as a pandemic disease and is declared as Public Health Emergency by the World Health Organisation. Accompanied with several harsh facts such as missing definitive treatment, lacking vaccine and difficult diagnosis, it is catching eyes of the people across the globe [1].

The name ZIKA came into origin based upon the place from where the first case of virus was identified late in 1947, which is ZIKA forest in Uganda [2]. The initial spread was found among primates. Rhesus monkeys found to be the first victims of this virus. After this, the disease subsequently shifted on to the human beings years after [3].

Primary cause of ZIKA virus is said to be the mosquito bites. A wide variety of mosquitoes are involved as vectors in the spread ranging from aedes agypti to aedes albopictus depending upon several areas from the Southwest to Asia. Mosquitoes generally become affected when they bite infected persons and then transfer the virus to healthy individuals via same mechanism [4].

First case of ZIKA was seen back in 1952 in humans. Then came the outbreak of 1987 in Africa and the latest was in 2015 in South America accounting thousands of causalities [5]. ZIKA virus infection showed positive correlation with microcephaly along with some severe brain anomalies [6].

Over viewing all these facts with a keen glance, a basic need urges to educate the masses worldwide and incorporate the baseline principles of ZIKA including its diagnosis, clinical features, differential diagnosis and treatment plan so as to prevent its outbreak. As it is a communicable disease, so health care professionals especially dentists should possess adequate knowledge about its mode of spread both in affected as well as unaffected regions. Keeping these views in mind, the present study was planned.

\section{Materials and Methods}

A cross sectional study was conducted in Luxmi Bai Institute of Dental Sciences \& Hospital, Patiala on the topic of ZIKA virus. The study included participation of interns, graduate staff and post graduate faculty. Study was conducted over a period of one month from January 2017 to February 2017. The aim and objective of the study was proposed to the head of the institution and an ethical permission was procured before starting the study.

A total number of 177 persons were included in the survey. The inclusions were made entirely on a voluntary basis. So, they were visited and questionnaire was distributed among them.

Questionnaire used was predominantly in English language. A wide variety of questions on the study topic were included. The coverage and 
content of the questions was further assessed by investigators for its validity and then finalised. Final questionnaire comprised of 19 questions in total. Questions were based upon the basic knowledge and other characteristic features of ZIKA virus and its prevention and treatment modalities. The main motive of the study and questionnaire designing was in accordance to make the participants aware about the topic of ZIKA virus, its severity and need to gather knowledge on it in dental practice.

\section{Data Analysis}

The study data was analysed using SPSS version 16.0. Descriptive statistics were attained including frequency distribution and mean values. Student's t-test and One way ANOVA were used to find the significance of difference regarding ZIKA awareness at $\mathrm{p}<0.05$.

\section{Results}

A total number of 210 people were contacted to participate in the study, however only $177(84.3 \%)$ out of them responded and voluntarily participated in the study. The sample consisted of $64(36.2 \%)$ male participants and $113(63.8 \%)$ female participants in total. The most dominant age group in the sample was of 21-30 years containing 125 participants, then came age group of 31-40 years comprising 33 personnel followed by 19 persons in 41 and above age group. When grouped according to qualification, there were 109 interns, 41 BDS and 27 MDS personnel in total sample.

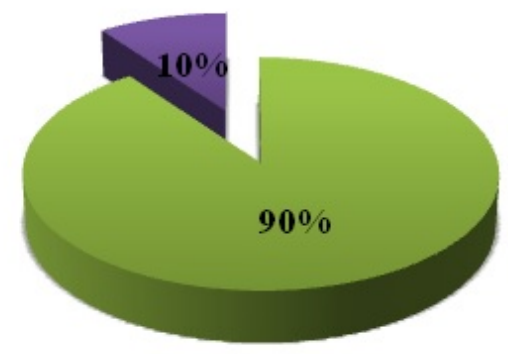

\section{Eungal \\ - Bacterial \\ viral \\ Not sure}

Figure 1: Showing response to different origins of ZIKA.

The total scores based upon the answers were analyzed with various graphs showing multiple values. It was evident from the questionnaire that $90 \%$ participants possessed knowledge about the viral origin of the condition. However, still remaining $10 \%$ were not sure about the answer as depicted (Figure 1). It was revealed that almost $88 \%$ practitioners were aware about the mosquito bite to be the main cause of the spread of ZIKA infection and rest were thinking of it as opportunistic infection (Figure 2). From the sample 60\% were rather sure about the name of ZIKA derived from its place of origin. On the contrary $21 \%$ were not sure about this. Also that $7 \%$ and $11 \%$ subjects thought about the name to be taken from virus name and species of insects respectively (Figure 3). Having a keen glance (Figure 4) depicts that approximately $53 \%$ participants were familiar with the fact that most recent outbreak of ZIKA occurred in South America; on the other hand 32\% thought it to be occurred in Africa, 11\% in Australia and only $5 \%$ thought about India (Figure 4 ). Moreover, $49 \%$ subjects were not sure about the correct incubation period of ZIKA virus to be 3-12 days. So, we got $29 \%$ correct answers only (Figure 5). Apart from these all, questions on vector for this condition, major abnormality of microcephaly due to this condition and major symptoms were included in the questionnaire to name a few (Figures 6 and 7).

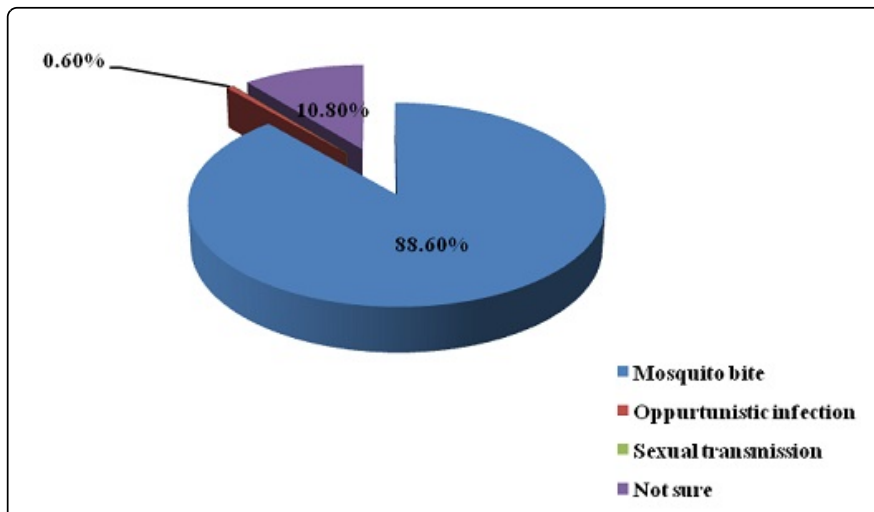

Figure 2: Showing primary cause of spread of ZIKA.

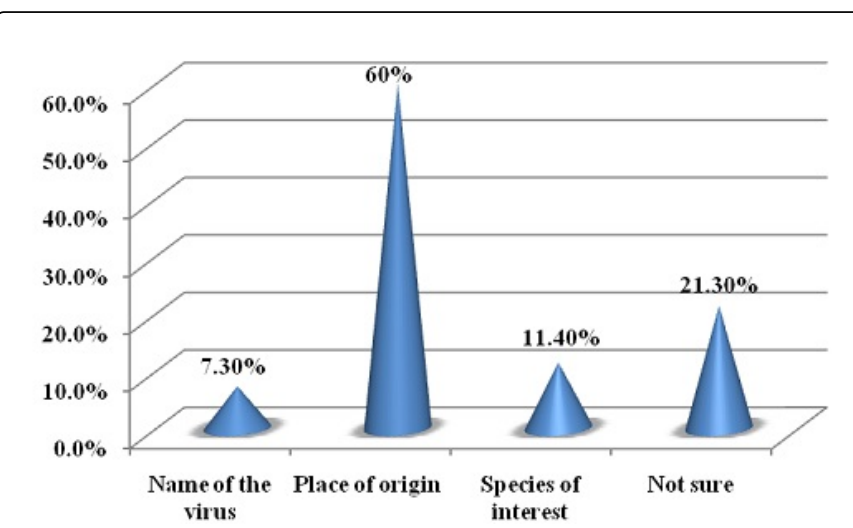

Figure 3: Name ZIKA is derived from.

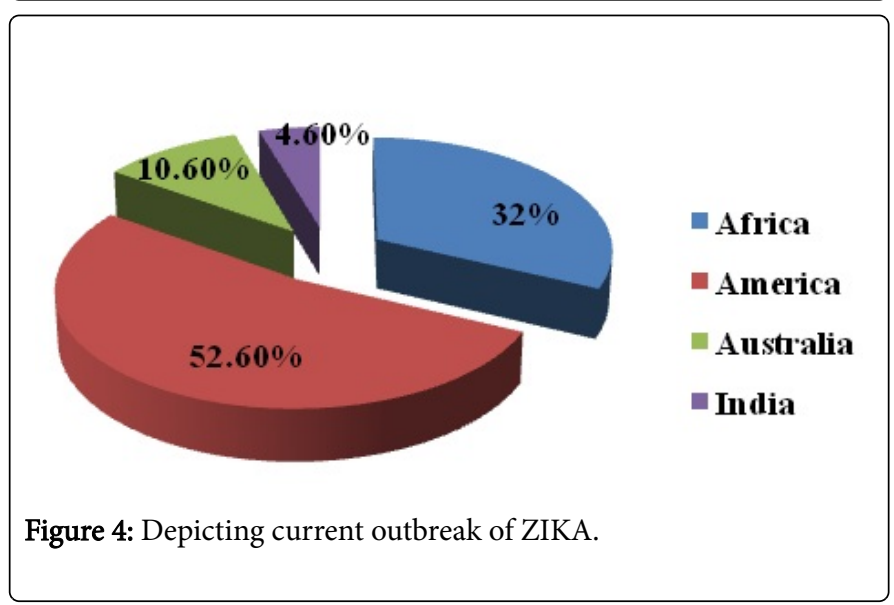


Citation: Singh M, Singh K, Puri MS, Anandani C, Singh HP, et al. (2017) Knowledge and Perception Towards Zika Outbreak In A Dental Institute. Dentistry 7: 420. doi:10.4172/2161-1122.1000420

Page 3 of 4

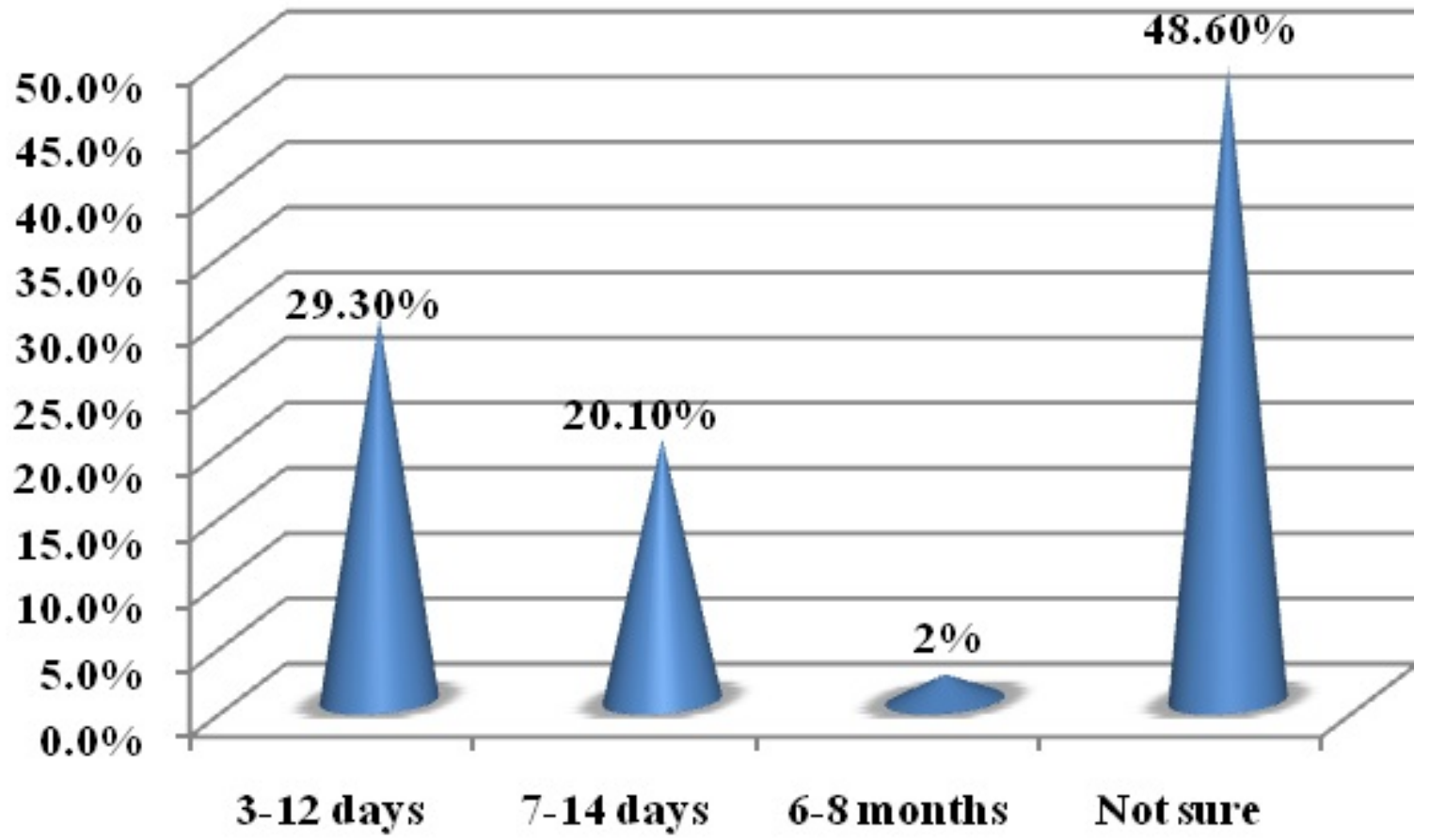

Figure 5: Incubation period of ZIKA.

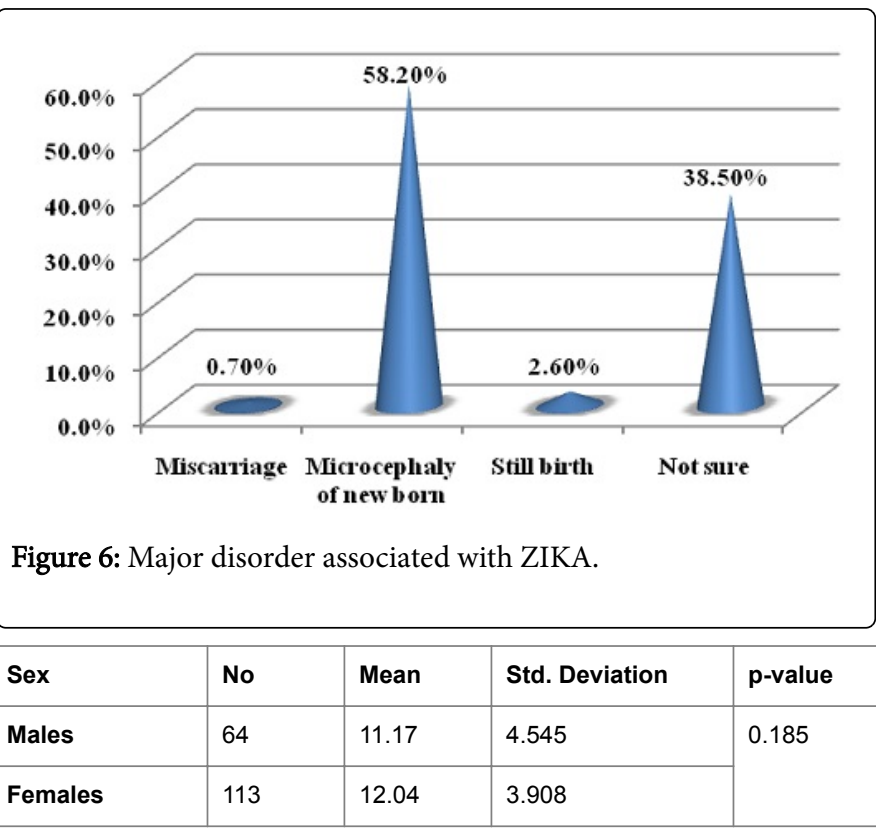

Table 1: Awareness of ZIKA virus among dental practitioners gender wise.

It was further noticed that female participants had greater knowledge regarding ZIKA outbreak compared to males as mentioned (Table 1). According to age groups, the middle age group had more scores compared to the counter parts, but the results were not significant (Table 2).

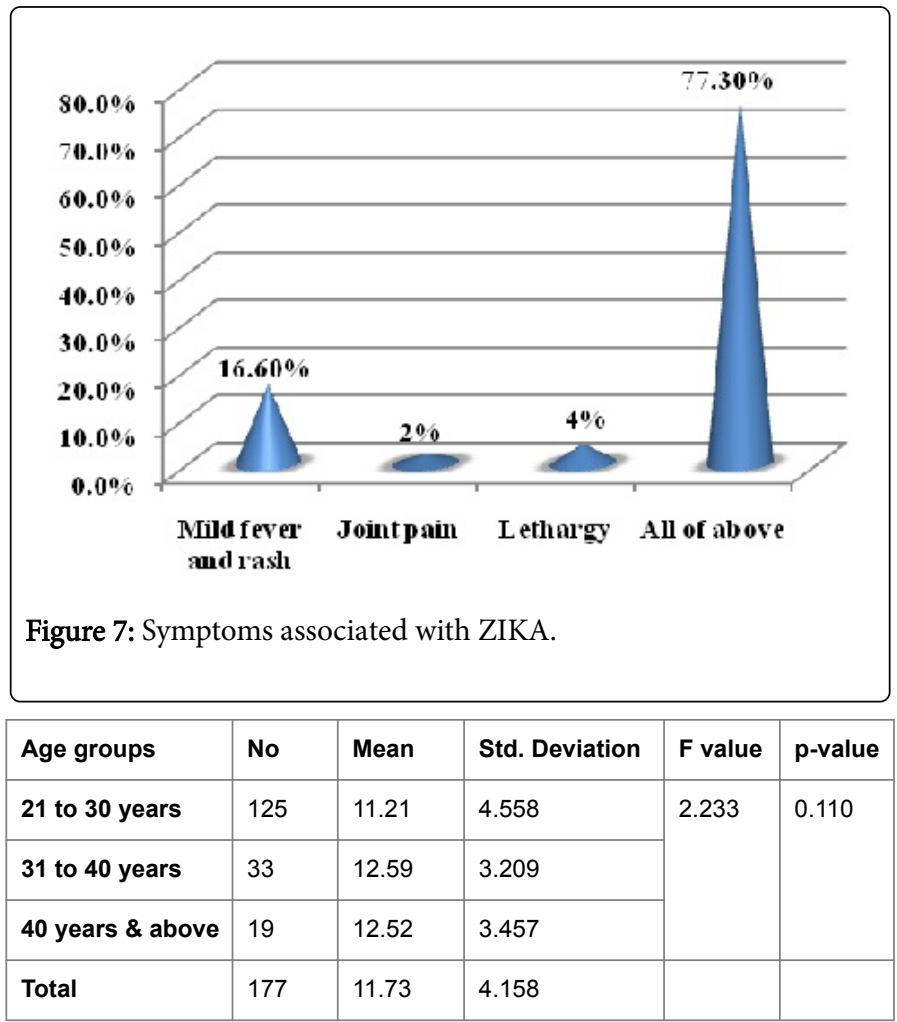

Table 2: Awareness of ZIKA virus among dental practitioners according to age. 
Whereas the level of education had a great impact on the awareness of ZIKA, which showed that the mean values were increasing significantly from interns to MDS faculty as illustrated (Table 3 ).

\begin{tabular}{|l|l|l|l|l|l|}
\hline Qualification & No & Mean & Std. Deviation & F value & p-value \\
\hline Interns & 109 & 11.62 & 4.415 & 3.732 & 0.026 \\
\hline BDS & 41 & 10.85 & 3.650 & & \\
\hline MDS & 27 & 14.00 & 2.028 & & \\
\hline Total & 177 & 11.73 & 4.158 & & \\
\hline
\end{tabular}

Table 3: Awareness of ZIKA virus among dental practitioners according to education.

\section{Discussion}

Historically has been found in Africa, Southeast Asia, and the Pacific Islands, now ZIKA is spreading its roots worldwide. Therefore, it becomes important for the entire healthcare personnel to evolve their knowledge regularly [7]. At present, with the boom in dental tourism in India, it becomes important that the dentists are able to identify and screen potential carriers for such diseases [8].

With reference to the present study, it is evident that with a mean value of $11.73 \pm 4.158$, which means approximately $61.7 \%$ subjects possessed knowledge about ZIKA. The knowledge about topics was found to be highest in MDS faculty followed by interns and then BDS. But these numbers are considerably low and it can also be assumed that lack of knowledge can result in possible transmission of the disease, and it becomes important that doctors can be acquainted with recent medical happenings from time to time regarding these recent outbreaks [9-13].

In accordance with the educational levels, highest mean scores recorded were $14.00 \pm 2.028$ for post graduate subjects (MDS). Next came the value of $11.62 \pm 4.415$ followed by value $10.85 \pm 3.650$ among interns and graduate participants. Some specific topic related questions incorporated in the study were not answered correctly by a fair number of people which expressed lack of knowledge and awareness about the topic. Such questions were like the vectors for ZIKA virus that is aedes agypti etc.

In contrast to this study, Aung et al, had observed good knowledge regarding Ebola virus disease during its outbreak in their study among nursing students which was approximately $54.7 \%$ in numerical value [14]. However, study conducted in Tricity among dental practitioners portrayed a similar result that is $61.8 \%$. [12].

The current data reported that females had better awareness about the pandemic disease compared to their counterparts. However, another cross sectional study by Iqbal et al, using pretested and validated questionnaires was conducted in AIMST University revealed that males with a mean average of 15.69 possessed less knowledge than females [15].

The recent study conducted may also contain some general limitations mainly due to cross sectional nature of study. Also the subjects were selected on a random basis and further participated voluntarily. Geographical limitation can also account up to some extent because the study conducted is in a particular city that is Patiala, and knowledge can vary geographically too. Other main factor which may have contributed to the lower educational level about this topic is that as there was no major outbreak in India in past, due to which dental professionals have lesser exposure and awareness about ZIKA virus.

\section{Conclusion}

In a crux, authors conclude that overall knowledge about ZIKA virus progresses with increasing age. But answers given to some questions about general topics of ZIKA were quite worrisome. However, dentists belong to a field which can help a lot with prevention and diagnosis of this condition. So a basic platform should be made to educate the dental and medical professionals, so as to guide the patients and masses to prevent the outbreak of the disease.

\section{References}

1. Gulland A (2016) Zika virus is a global public health emergency, declares WHO. BMJ 35: 657.

2. Plourde AR, Bloch EM (2016) A Literature Review of Zika Virus. Emerg Infect Dis 22: 1185-1192.

3. Mishra A (2016) The Emergence of Zika Virus (ZiV): A Review. J Biotechnol Biomater 6: 1-3.

4. Angela FH, Derric N, Andrew RM, Nick K, Sarah S, et al. (2011) Field performance of engineered male mosquitoes. Nature Biotechnology 29: 1034- 1037.

5. Galán-Huertaa KA, Rivas-Estillaa AM, Martinez-Landeros EA, Arellanos-Sotoa D, Ramos-Jimenez J (2016) The Zika virus disease: An overview. Medicina Universitaria 18: 115-124.

6. Sonja RA, Jamieson DJ, Honein MA, Petersen LR (2016) Zika Virus and Birth Defects -Reviewing the Evidence for Causality. N Engl J Med 20: 1981-1987.

7. Mazmanian PE, Davis DA, Galbraith R (2009) American College of Chest Physicians Health and Science Policy Committee. Continuing medical education effect on clinical outcomes: Effectiveness of continuing medical education: American College of Chest Physicians EvidenceBased Educational Guidelines. Chest 1353 Suppl: 49S55S.

8. Ratnapalan S, Uleryk E (2014) Organizational learning in health care organizations. Systems 2: 24-33.

9. Fazekas B, Fazekas J, Moledina M, Fazekas B, Karolyhazy K (2015) Ebola virus disease: Awareness among junior doctors in England. J Hosp Infect 90: 260-262.

10. Lisk C, Snell L, Haji-Coll M, Ellis J, Sufi S, et al. (2015) Doctors' knowledge of viral hemorrhagic fevers. Acute Med 14: 47-52.

11. Valerio L (2015) When information does not translate into knowledge. Ebola and hemorrhagic fevers knowledge among primary care physicians and nurses. Open J Prev Med 5: 122-127.

12. Gupta N, Mehta N, Gupta P, Arora V, Setia P (2015) Knowledge regarding Ebola hemorrhagic fever among private dental practitioners in Tricity, India: A cross sectional questionnaire study. Niger Med J 56: 138-142.

13. Aung MH, Oo WM, Lynn KK, Mya KM (2015) Knowledge and perception towards Ebola virus disease among nursing students in the University of Nursing, Yangon. Myanmar Med J 57: 8-14.

14. Apichaya S, Chaninat R, Theerin C, Supataradit B, Awapa P, et al. (2016) Knowledge, Attitude and Practice of Pandemic H1N1 Influenza Prevention in Thailand.

15. Iqbal MZ, Lokanayagi SS, Rahul R, Kumar S, Tahir M (2016) Knowledge, Attitude And Perception Of Zika Virus Among Healthcare Students Of Medicine, Pharmacy And Dentistry Of Aimst University. The journal of the international society for pharmacoeconomics and outcomes research 19: A484. 